\title{
Pharmacokinetic evaluation of the interaction between oral kaempferol and ethanol in rats
}

\author{
ZHAOXIANG ZHOU ${ }^{1}$ \\ MENG WANG $^{1}$ \\ ZENGJUN GUO ${ }^{2}$ \\ XIAOYING ZHANG ${ }^{1 *}$ \\ ${ }^{1}$ College of Veterinary Medicine \\ Northwest AEF University, Yangling \\ Shaanxi 712100, China \\ ${ }^{2}$ School of Pharmacy \\ Xi'an Jiaotong University \\ Xi'an Shaanxi 710061, China
}

Accepted July 25, 2016

Published online August 2, 2016

\begin{abstract}
This study was aimed at investigating the effect of ethanol on oral bioavailability of kaempferol in rats, namely, at disclosing their possible interaction. Kaempferol (100 or 250 $\mathrm{mg} \mathrm{kg}^{-1} \mathrm{bm}$ ) was administered to the rats by oral gavage with or without ethanol $\left(600 \mathrm{mg} \mathrm{kg}^{-1} \mathrm{bm}\right)$ co-administration. Intravenous administration (10 and $25 \mathrm{mg} \mathrm{kg}^{-1} \mathrm{bm}$ ) of kaempferol was used to determine the bioavailability. The concentration of kaempferol in plasma was estimated by ultra high performance liquid chromatography. During coadministration, a significant increase of the area under the plasma concentration-time curve as well as the peak concentration were observed, along with a dramatic decrease in total body clearance. Consequently, the bioavailability of kaempferol in oral control groups was $3.1 \%$ (100 mg kg-1 $\mathrm{bm})$ and $2.1 \%\left(250 \mathrm{mg} \mathrm{kg}^{-1} \mathrm{bm}\right)$. The first was increased by $4.3 \%$ and the other by $2.8 \%$ during ethanol co-administration. Increased permeability of cell membrane and ethanolkaempferol interactions on CYP450 enzymes may enhance the oral bioavailability of kaempferol in rats.
\end{abstract}

Keywords: kaempferol, bioavailability, pharmacokinetics, ethanol, cytochrome P450s

As a representative flavonoid, kaempferol (3,4,5,7-tetrahydroxyflavone, $\left.M_{\mathrm{r}} 286.2\right)$ is mostly distributed in medicinal plants, vegetables and fruits (1). In clinics, numerous studies have demonstrated that kaempferol possesses far-ranging pharmacological activities, especially antioxidant (2) and anti-cancer ones (3). However, the oral bioavailability of kaempferol is relatively low because of its low lipid solubility and its limited membrane permeability (4). Some reports indicate that the efficiency of intestinal absorption of some flavones is strongly affected by their solubility in the vehicles (5). Consequently, the therapeutic effect of kaempferol is restricted to oral administration (4).

Alcoholic liver disease is caused by consuming a large quantity of alcoholic beverages over a long period of time. It has been reported that ethanol enhances flavone solubility (6). Kaempferol is a flavone with a protective role against alcoholic liver injury (7). In addi-

\footnotetext{
*Correspondence; e-mail: zhang.xy@nwsuaf.edu.cn
} 
tion, the metabolism of both kaempferol and ethanol is mediated by cytochrome P450 enzymes. Can the intestinal absorption of kaempferol be enhanced by ethanol? Does interaction happen between ethanol and kaempferol? This study was aimed at answering these questions.

\section{EXPERIMENTAL}

\section{Materials}

Kaempferol was purchased from Sigma Chemical Co. (USA). HPLC-grade methanol and acetonitrile were purchased from Merck Co. Ltd. (Germany). All other reagents were of analytical grade.

\section{Animal treatment}

Twenty-four male Sprague Dawley rats weighing 250-300 g (aged 2-3 months) were obtained from the Experimental Animal Center of the Fourth Military Medical University (Xi'an, China). Animals were housed in a temperature-controlled room under 12-hour light-dark cycles. Animals had free access to food and water during the experimental period. All animal experimental protocols were reviewed and approved by the Ethical Committee of Northwest A\&F University for the Care and Use of Laboratory Animals (Yangling, China).

Kaempferol suspension for intravenous administration was prepared by mixing in distilled water and a kaempferol solution for oral administration was prepared by dissolving kaempferol in ethanol.

The rats were randomly divided into six groups of four animals each: group 1 - low dose p.o., control group, administered $100 \mathrm{mg} \mathrm{kg}^{-1} \mathrm{bm}$ kaempferol dissolved in corn oil; group 2 - high dose p.o. control group, administered $250 \mathrm{mg} \mathrm{kg}^{-1} \mathrm{bm}$ kaempferol dissolved in corn oil; group 3 - low dose p.o. combination group, administered $100 \mathrm{mg} \mathrm{kg}^{-1} \mathrm{bm}$ kaempferol dissolved in ethanol $\left(600 \mathrm{mg} \mathrm{kg}^{-1} \mathrm{bm}\right)$; group 4 - high dose p.o. combination group, administered $250 \mathrm{mg} \mathrm{kg}^{-1} \mathrm{bm}$ kaempferol dissolved in ethanol $\left(600 \mathrm{mg} \mathrm{kg}^{-1} \mathrm{bm}\right)$; group 5 - low dose i.v. control group, administered $10 \mathrm{mg} \mathrm{kg}^{-1} \mathrm{bm}_{\text {kaempferol suspended }}$ in distilled water; group 6 - high dose i.v. control group, administered $25 \mathrm{mg} \mathrm{kg}^{-1} \mathrm{bm}$ kaempferol suspended in distilled water.

To determine drug concentrations and to calculate the pharmacokinetic parameters, blood samples were drawn from the jugular vein using heparinized tubes at specified time intervals: 15, 30, 60, 90, 120, 240, 360, 480 and 720 min after administration. Blood samples were centrifuged at $3000 \mathrm{rpm}$ for $10 \mathrm{~min}$ at $4{ }^{\circ} \mathrm{C}$ and the plasma was stored at $-20^{\circ} \mathrm{C}$ until HPLC analysis.

\section{Sample preparation}

A hundred $\mu \mathrm{L}$ of plasma with $50 \mu \mathrm{L} \mathrm{HCl}\left(10 \mathrm{~mol} \mathrm{~L}^{-1}\right)$ and $100 \mu \mathrm{L}$ acetonitrile was vortex-mixed for $3 \mathrm{~min}$. The resulting mixture was kept in a water bath at $90^{\circ} \mathrm{C}$ for $120 \mathrm{~min}$ and then $25 \mu \mathrm{L}$ of $\mathrm{NH}_{4} \mathrm{OH}\left(7.5 \mathrm{~mol} \mathrm{~L}^{-1}\right)$ was added. After $1.5 \mathrm{~mL}$ acetonitrile was added, the cooled sample was mixed thoroughly by vortex mixing for $2 \mathrm{~min}$ and centrifuged at 10,000 
rpm for $15 \mathrm{~min}$. The supernatant was discarded and the pellet with precipitated proteins was dried under a gentle stream of nitrogen at $38^{\circ} \mathrm{C}(8)$. The residue was dissolved in 100 $\mu \mathrm{L}$ methanol and centrifuged at 15,000 rpm for $10 \mathrm{~min}$. Finally, $20 \mu \mathrm{L}$ of the supernatant was injected into the HPLC system for the measurements.

\section{Ultra-high performance liquid chromatography (UHPLC)}

Filtered solutions were analyzed by UHPLC (Waters Acquity, USA) using a Waters BEH C18 column $(1.7 \mu \mathrm{m}, 50 \times 2.5 \mathrm{~mm})$. The mobile phase was a mixture of methanol and

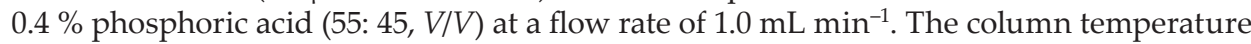
was $35^{\circ} \mathrm{C}$ and the UV detector wavelength was set at $360 \mathrm{~nm}(8)$.

\section{Pharmacokinetic analysis}

Model fitting and evaluation of the pharmacokinetic parameters were done using Drug and statistics 2.0 (DAS 2.0; Drug Clinical Research Center of Shanghai University of Traditional Chinese Medicine, Shanghai, China). Pharmacokinetic parameters were determined using the non-compartmental method based on the statistical moment theory. The area under the plasma concentration time curve $(A U C)$ was calculated by the linear trapezoidal method. The apparent elimination half-life $\left(t_{1 / 2}\right)$ was calculated by $0.693 / k(k-$ the elimination rate constant). Total body clearance $\left(\mathrm{CL}_{\mathrm{z}} / F\right)$ was calculated by dose/AUC. Visual inspection of the data from the concentration-time curve was used to obtain the peak concentration $\left(c_{\max }\right)$ and the time to reach peak concentration $\left(t_{\max }\right)$ of kaempferol in plasma. The apparent volume of distribution $\left(V_{\mathrm{z}}\right)$ was calculated by: dose $\times A U C M / A U C \times A U C$ (AUCM - area under the first moment of the concentration-time curve from time zero to infinity). Absolute bioavailability $(F, \%)$ was estimated from the equation:

$$
\left(A U C_{\text {p.o. }} \times \operatorname{dose}_{\text {i.v. }} / \text { dose }_{\text {p.o. }} \times A U C_{\text {i.v. }}\right) \times 100 .
$$

\section{Statistical analysis}

All results are presented as mean \pm standard deviations (SD). Statistical analysis was performed using Student's $t$-test. A value of $p<0.05$ was taken as the level of significance.

\section{RESULTS AND DISCUSSION}

The plasma concentration time-course of kaempferol following oral administration of kaempferol with or without ethanol $\left(600 \mathrm{mg} \mathrm{kg}^{-1} \mathrm{bm}\right)$ is illustrated in Fig. 1 and the following intravenous administration in Fig. 2. Pharmacokinetic parameters of kaempferol are listed in Table I.

Compared to the oral control groups (100 and $250 \mathrm{mg} \mathrm{kg}^{-1} \mathrm{bm}$ of kaempferol), the significantly decreased area under the plasma concentration-time curve and the concentration peak of oral kaempferol showed that co-administration of ethanol improved kaempferol absorption (100 $\left.\mathrm{mg} \mathrm{kg}^{-1} \mathrm{bm}, p<0.05 ; 250 \mathrm{mg} \mathrm{kg}^{-1} \mathrm{bm}, p<0.01\right)$. Decreased total body clearance $\left(\mathrm{CL}_{\mathrm{z}} / F\right)$ in the case of ethanol co-administration $\left(100 \mathrm{mg} \mathrm{kg}^{-1} \mathrm{bm}, p<0.05\right.$ 


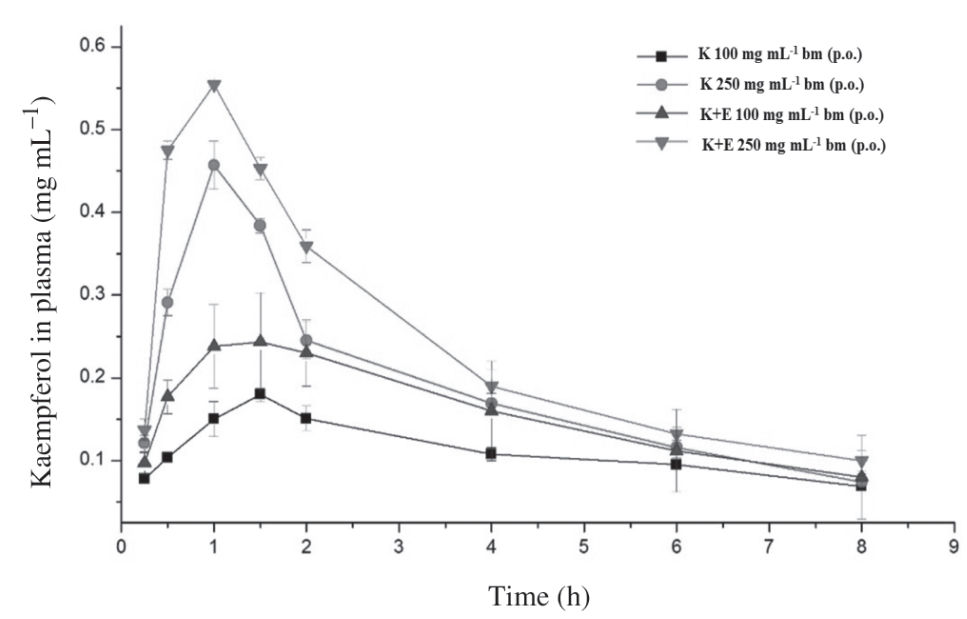

Fig. 1. Mean plasma concentration after oral administration of kaempferol (K) (100 and $250 \mathrm{mg} \mathrm{kg}^{-1}$ $\mathrm{bm}, n=4)$ with or without ethanol $(\mathrm{E})$, in rats. Bars represent the standard deviation.

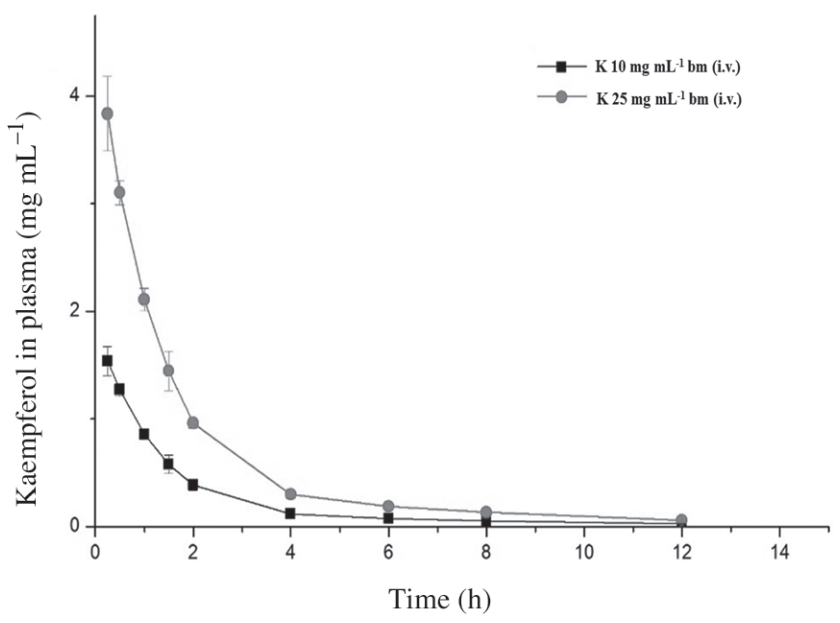

Fig. 2. Mean plasma concentration after intravenous (10 and $\left.25 \mathrm{mg} \mathrm{kg}^{-1} \mathrm{bm}, n=4\right)$ administration of kaempferol $(\mathrm{K})$, in rats. Bars represent the standard deviation.

and $\left.250 \mathrm{mg} \mathrm{kg}^{-1} \mathrm{bm}, \mathrm{p}<0.05\right)$ indicated reduced clearance of kaempferol. Since drug bioavailability $(F)$ depends on the extent of absorption and the rate of total body clearance, in oral control groups it was $3.1 \%\left(100 \mathrm{mg} \mathrm{kg}^{-1} \mathrm{bm}\right)$ and $2.1 \%\left(250 \mathrm{mg} \mathrm{kg}^{-1} \mathrm{bm}\right)$ for kaempferol but it was significantly increased by $4.3 \%$, namely, $2.8 \%(p<0.05$ and $p<0.01$, resp.) during ethanol co-administration. Meanwhile, the apparent volume of distribution $\left(V_{\mathrm{z}}\right)$ and the time to reach $c_{\max }\left(t_{\max }\right)$ of kaempferol after oral co-administration of ethanol changed, but not significantly. 
Table I. Pharmacokinetic parameters following intravenous and peroral administration of kaempferol with or without ethanol

\begin{tabular}{|c|c|c|c|c|c|c|}
\hline \multirow{2}{*}{ Parameter } & \multicolumn{2}{|c|}{$\begin{array}{l}\text { Kaempferol } \\
\left(\mathrm{mg} \mathrm{kg}^{-1}, \text { i.v. }\right)\end{array}$} & \multicolumn{2}{|c|}{$\begin{array}{l}\text { Kaempferol } \\
\left(\mathrm{mg} \mathrm{kg}^{-1}, \text { p.o. }\right)\end{array}$} & \multicolumn{2}{|c|}{$\begin{array}{l}\text { Kaempferol + ethanol } \\
\quad\left(\mathrm{mg} \mathrm{kg}^{-1}, \text { p.o. }\right)\end{array}$} \\
\hline & 10 & 25 & 100 & 250 & 100 & 250 \\
\hline $\begin{array}{l}\text { AUC } \\
\left(\mathrm{mg} \mathrm{L}^{-1} \mathrm{~h}^{-1}\right)\end{array}$ & $2.89 \pm 0.18$ & $7.17 \pm 0.41$ & $0.89 \pm 0.02$ & $1.51 \pm 0.07$ & $1.24 \pm 0.12^{*}$ & $1.93 \pm 0.06^{\# \#}$ \\
\hline$t_{1 / 2}(\mathrm{~h})$ & $3.51 \pm 0.19$ & $3.45 \pm 0.12$ & $5.34 \pm 0.66$ & $3.47 \pm 0.70$ & $3.59 \pm 0.82^{*}$ & $2.70 \pm 0.09^{\#}$ \\
\hline$t_{\max }(\mathrm{h})$ & 0.25 & 0.25 & 1.50 & 1.00 & 1.50 & 1.00 \\
\hline $\begin{array}{l}\mathrm{CL}_{\mathrm{z}} / F \\
\left(\mathrm{~L} \mathrm{~kg} \mathrm{~h}^{-1}\right)\end{array}$ & $3.33 \pm 0.22$ & $3.36 \pm 0.20$ & $70.71 \pm 4.344$ & $130.99 \pm 14.356$ & $60.59 \pm 6.54^{*}$ & $110.90 \pm 5.321^{\#}$ \\
\hline$V_{\mathrm{z}}\left(\mathrm{L} \mathrm{kg}^{-1}\right)$ & $16.82 \pm 0.54$ & $16.70 \pm 0.59$ & $\begin{array}{c}1665.51 \pm \\
110.80\end{array}$ & $1573.01 \pm 150.32$ & $1458.78 \pm 173.82$ & $1360.21 \pm 56.73$ \\
\hline $\begin{array}{l}c_{\max } \\
\left(\mathrm{mg} \mathrm{L}^{-1}\right)\end{array}$ & $1.54 \pm 0.14$ & $3.84 \pm 0.34$ & $0.18 \pm 0.01$ & $0.46 \pm 0.03$ & $0.26 \pm 0.01^{*}$ & $0.59 \pm 0.02^{\#}$ \\
\hline$F(\%)$ & - & - & $3.07 \pm 0.05$ & $2.11 \pm 0.10$ & $4.30 \pm 0.42^{*}$ & $2.69 \pm 0.21^{\# \#}$ \\
\hline
\end{tabular}

Significant difference compared to: $100 \mathrm{mg} \mathrm{kg}^{-1} \mathrm{bm}$ kaempferol group; ${ }^{*} p<0.05,{ }^{* *} p<0.01 ; 250 \mathrm{mg} \mathrm{k}^{-1} \mathrm{bm} \mathrm{kaempferol}^{2}$ group: ${ }^{\#} p<0.05,{ }^{\# \#} p<0.01$.

Ethanol dose is $600 \mathrm{mg} \mathrm{kg}^{-1} \mathrm{bm}$.

Flavonoid absorption is affected by the permeability of the membrane (9). It is known that ethanol could enhance the cell membrane permeability by breaking cell-membrane integrity and stability (10), co-administration of ethanol could therefore accelerate the absorption of kaempferol. Three cytochrome P450s enzymes, CYP2E1, CYP1A2 and CYP3A4, play a major role in ethanol metabolism in the liver $(11,12)$, and CYP1A2 is also involved in the metabolism of kaempferol, as confirmed in a previous in vitro study (13). As a potent inhibitor of CYP2E1 and CYP 3A4, kaempferol can inhibit ethanol metabolism $(14,15)$. In our investigations, kaempferol and ethanol co-administration clearly increased the AUC (Fig. 1) and bioavailability (Table I) of kaempferol, suggesting that competition of ethanol and kaempferol on CYP1A2 may inhibit kaempferol metabolism.

\section{CONCLUSIONS}

The fact that ethanol co-administration enhances bioavailability of kaempferol demonstrated the vital role of kaempferol in protection against alcoholic liver diseases. This study may be helpful for medical exploration in alcoholic liver disease interventions.

Acknowledgments. - This work was supported by the Overseas Cultural \& Educational Experts funded by the State Administration for Foreign Experts Affairs (X2015016, Northwest A\&F University); Key Construction Program of International Cooperation Base in S\&T (2015SD0018), Shaanxi Province; Ministry of Education and State Administration of Foreign Experts Affairs "overseas teacher" project (MS2011XBNL057), China. 


\section{REFERENCES}

1. S. H. Häkkinen, S. O. Kärenlampi, I. M. Heinonen, H. M. Mykkänen and A. R. Törrönen, Content of the flavonols quercetin, myricetin, and kaempferol in 25 edible berries, J. Agric. Food Chem. 47 (1999) 2274-2279; DOI: 10.1021/jf9811065.

2. J. S. Park, H. S. Rho, D. H. Kim and I. S. Chang, Enzymatic preparation of kaempferol from green tea seed and its antioxidant activity, J. Agric. Food Chem. 54 (2006) 2951-2956; DOI: 10.1021/ jf052900a.

3. A. Y. Chen and Y. C. Chen, A review of the dietary flavonoid, kaempferol on human health and cancer chemoprevention, Food Chem. 138 (2013) 2099-2107; DOI: 10.1016/j.foodchem.2012.11.139.

4. A. Barve, C. Chen, V. Hebbar, J. Desiderio, C. L. Saw and A. Kong, Metabolism, oral bioavailability and pharmacokinetics of chemopreventive kaempferol in rats, Biopharm. Drug Dispos. 30 (2009) 356-365; DOI: 10.1002/bdd.677.

5. M. K. Piskula and J. Terao, Quercetin's solubility affects its accumulation in rat plasma after oral administration, J. Agric. Food Chem. 10 (1998) 4313-4317; DOI: 10.1021/jf980117v.

6. E. Saidman, A. Yurquina, R. Rudyk, M. A. A. Molina and F. H. Ferretti, A theoretical and experimental study on the solubility, dissolution rate, structure and dipolar moment of flavone in ethanol, J. Mol. Struct. (Theochem) 585 (2002) 1-13; DOI: 10.1016/S0166-1280(02)00027-1.

7. M. Wang, J. Sun, Z. Jiang, W. Xie and X. Zhang, Hepatoprotective effect of kaempferol against alcoholic liver injury in mice, Am. J. Chin. Med. 43 (2015) 241-254; DOI: 10.1142/S0192415X15500160.

8. Y. Qin, N. Zhou, Q. Gong and Z. Zhou, Effect of glycyrrhetinic acid on the plasma concentration of kaempferol in rats, Chinese J. Exp. Trad. Med. Form. 19 (2013) 183-187; DOI: 10.11653/syfj2013160183.

9. V. Crespy, C. Morand, C. Besson, N. Cotelle, H. Vézin, C. Demigné and C. Rémésy, The splanchnic metabolism of flavonoids highly differed according to the nature of the compound, Am. J. Physiol. Gastrointest. Liver Physiol. 284 (2003) G980-G988; DOI: 10.1152/ajpgi.00223.2002.

10. X. Q. Wang, Y. J. Yuan, J. C. Li and C. Chen, Changes of cell membrane permeability induced by DMSO and ethanol in suspension cultures of Taxus cuspidata, Adv. Mater. Res. 236-238 (2011) 942-948; DOI: 10.4028/www.scientific.net/AMR.236-238.942.

11. K. S. Salmela, I. G. Kessova, I. B. Tsyrlov and C. S. Lieber, Respective roles of human cytochrome P-4502E1, 1A2, and 3A4 in the hepatic microsomal ethanol oxidizing system, Alcohol Clin. Exp. Res. 22 (1998) 2125-2132; DOI: 10.1111/j.1530-0277.1998.tb05926.x.

12. C. S. Lieber, Microsomal ethanol-oxidizing system (MEOS): the first 30 years (1968-1998)-a review, Alcohol Clin. Exp. Res. 23 (1999) 991-1007; DOI: 10.1111/j.1530-0277.1999.tb04217.x.

13. V. Breinholt, E. A. Offord, C. Brouwer, S. E. Nielsen, K. Brøsen and T. Friedberg, In vitro investigation of cytochrome P450-mediated metabolism of dietary flavonoids, Food Chem. Toxicol. 40 (2002) 609-616; DOI: 10.1016/S0278-6915(01)00125-9.

14. D. Pal and A. K. Mitra, MDR- and CYP3A4-mediated drug-herbal interactions, Life Sci. 78 (2006) 2131-2145; DOI: 10.1016/j.lfs.2005.12.010

15. T. Y. Shih, T. H. Young, H. S. Lee, C. B. Hsieh and O. Y. Hu, Protective effects of kaempferol on isoniazid- and rifampicin-induced hepatotoxicity, AAPS J. 15 (2013) 753-762; DOI: 10.1208/s12248013-9490-6. 